\title{
MODEL HAZARD UNTUK LAJU KERUSAKAN PIPA AIR BERDASARKAN DATA TERSENSOR TIPE II YANG BERDISTRIBUSI LOGNORMAL
}

\author{
Eduardus Beo Seso Delvion \\ Program Studi Pendidikan Matematika, Universitas Timor \\ ebs.delvion@yahoo.com
}

Diterima:. Disetujui: Dipublikasikan:

\begin{abstract}
ABSTRAK
Air bersih merupakan kebutuhan dasar bagi makluk hidup dalam kehidupan sehari-hari. Untuk mempermudah pendistribusian air dari sumber air ke tempat tujuan diperlukan sarana penghubung yaitu pipa air yang dirancang sebagai jaringan pipa air. Masa pemakaian pipa dibatasi oleh waktu mengenai daya tahan pipa tersebut sehingga rentan terhadap kerusakan pipa semakin besar berjalannya waktu. Oleh karna itu dalam penulisan ini, untuk menentukan laju kerusakan pipa yang diuji pada suatu keadaan tertentu maka dilakukan analisis laju kerusakan suatu komponen yang dikenal dengan analisis model hazard yang dikembangkan dari analisis reliabilitas. Tujuannya untuk menentukan model hazard untuk laju kerusakan pipa air berdasarkan data tersensor tipe ii yang berdistribusi lognormal. Hasil pengolahan dari data jaringan pipa DMA Buring 3F dengan nilai estimasi untuk diperoleh nilai parameter dari distribusi lognormal yaitu $\hat{\mu}_{\ln t}=3,6853$ dan $\hat{\sigma}_{\ln t}=0,2979$ sehingga diperoleh laju kerusakan pipa berumur 45 dan 55 tahun masing-masing yaitu 0,024 dan 0,029.
\end{abstract}

Kata kunci: Model hazard, Model reliabilitas, Distribusi lognormal, Data tersensor tipe ii

\begin{abstract}
Clean water is a basic requirement for living creatures in everyday life. To facilitate the distribution of water from a water source to the destination, a water pipe is needed in this plan, which is designed as a water pipe network. The pipeline usage period is limited by time regarding the durability of the pipe so that it is vulnerable to damage to the pipeline the greater the time. Therefore, in this paper, to determine the rate of pipeline damage tested in a particular situation, the damage rate analysis of a component is known as hazard model analysis developed from reliability analysis. The aim is to determine the hazard model for the rate of damage to the water pipe based on type II censored data which is lognormal distribution. The results of DMA Buring 3F pipeline network with an estimated value to obtain parameter values from the lognormal distribution, namely $\hat{\mu}_{\ln t}=3,6853$ and $\hat{\sigma}_{\ln t}=0,2979$ so that the pipeline damage rate is 45 and 55 years old respectively 0.024 and 0.029 .
\end{abstract}

Keywords: Hazard model, Reliability model, Lognormal distribution, Censored data type ii

\section{Pendahuluan}

Analisis reliabilitas merupakan teknik statistik yang berguna menganalisis variabel random positif mencakup waktu reliabilitas dan waktu kegagalan. Laju kegagalan (failure rate) atau yang dikenal dengan fungsi hazard yang analogi dengan laju perbaikan (repair rate) merupakan pengembangan dari fungsi reliabilitas (Rausand dan Hoyland, 2004). Coz (1972) mengembangkan model hazard dengan mencari estimator untuk menentukan parameter yang bersesuaian dengan menganalisis data waktu kegagalan yang tersensor. Analisis data uji ketahanan suatu komponen dibutuhkan data yang meliputi waktu ketahan komponen dan status waktu ketahan komponen dari sampel yang diteliti. Data waktu uji ketahan yang diperoleh dapat berupa data data tersensor tipe I jika data diamati sampai waktu yang ditentukan berakhir dan data tersensor tipe II merupakan data hasil penelitian dimana penelitian dihentikan setelah terjadi kegagalan (Lawless, 2003). Untuk menganalisis data reliabilitas perlu diperhatikan dalam pemilihan model yang bersifat parametrik atau nonparametrik. Pada kasus ini digunakan model yang bersifat 


\section{Jurnal Pendidikan Matematika Vol 1 No 1 Tahun 2019 Nama Penulis}

parametrik dikarenakan data tersensor memerlukan asumsi tertentu mengenai distribusi populasinya. Beberapa distribusi parametrik yang popular dan dapat digunakan untuk menganalisis model reliabilitas adalah distribusi eksponensial, weibull, distribusi gamma, distribusi poisson dan lain-lain. Dube, dkk. (2011) mengajukan model estimasi parameter hybrid censored dengan pendekatan algoritma EM (Expectation Maximization) dan maksimum likelihood menggunakan distribusi lognormal. Aplikasi distribusi lognormal yang pada kenyataannya tidak merepresentasikan daya tahan komponen-komponen karena tidak memiliki pertimbangan-pertimbangan sebagai distribusi yang penting dalam reliabilitas, melainkan distribusi lognormal sangat penting digunakan sebagai distribusi untuk waktu perbaikan komponen-komponen yang mengalami kegagalan atau kerusakan sehingga dianggap lebih realistis. Panahi dan Asadi (2011) mengajukan model estimasi distribusi weibull untuk data tersensor tipe II dengan menggunakan metode estimastor bayes under linex loss. Distribusi weibull memuat dua parameter yang aplikasinya tidak hanya penting dalam masalah reliabilitas tetapi juga terkait masalah gangguan sinyal yang berhubungan dengan sistem komunikasi. Delvion, dkk. (2018) menggunakan distribusi rayleigh dengan pendekatan minimum cut set untuk menghitung kehandalan dari sebuah jaringan pipa air. Dari beberapa distribusi di atas yang telah diketahui, penulis merasa perlu menggunakan distribusi lognormal untuk menentukan model hazard laju kerusakan pipa air berdasarkan data tersensor tipe ii.

\section{Metode Penelitian}

\section{Desain}

Metode yang digunakan dalam penelitian ini ialah kajian pustaka dan studi kasus. Melalui referensi pustaka dan data yang diperoleh dari hasil pengamatan dalam menentukan model yang baik mengenai model hazard untuk laju kerusakan pipa air berdasarkan data tersensor tipe ii yang berdistribusi lognormal.

2. Lokasi dan Pengumpulan Data

Lokasi yang dipilih untuk memperoleh data kerusakan pipa air ialah dalam lingkup kota Malang yang tersusun atas beberapa DMA (District Meter Area). Dalam penelitian ini, peneliti memilih DMA Buring 3F yang berlokasi di kecamatan Kedungkandang dengan jumlah 50 sampel yang berdiameter 50 mm dan masa pakai pipa selama 19 tahun yang berjenis PVC.

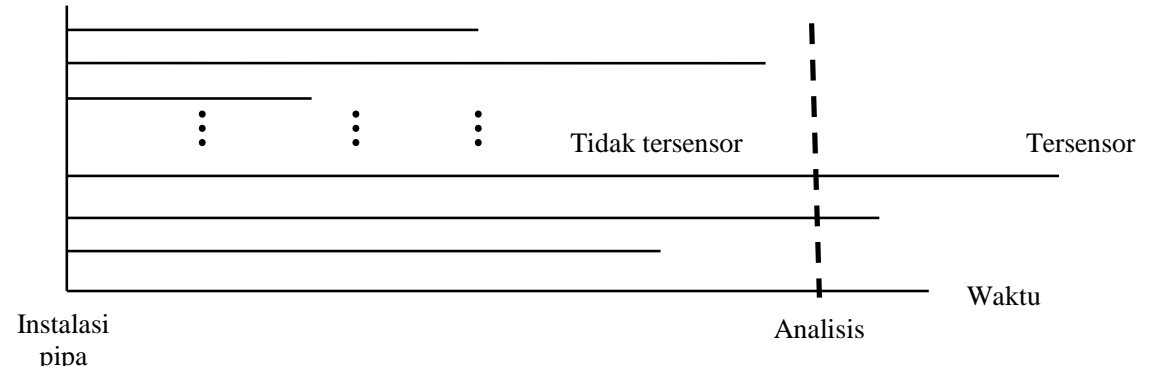

3. Prosedur Pelaksanaan

Gambar 1. Ilustrasi Data Tersensor Tipe II

Prosedur pelaksanaan dibagi menjadi beberapa tahapan, yaitu:

- Menentukan estimator dari model distribusi lognormal dengan metode maksimum likelihood

- Mengkonstruksi model hazard dari model reliabilitas untuk data tersensor tiper ii berdasarkan distribusi lognormal.

- Penerapan model hazard untuk laju kerusakan pipa air berdasarkan data tersensor tipe ii yang berdistribusi lognormal. 


\section{Jurnal Pendidikan Matematika Vol 1 No 1 Tahun 2019 Nama Penulis}

\section{Hasil Penelitian dan Pembahasan}

Data tersensor tipe II merupakan data $r$ yang diperoleh dari pengamatan $n$ sampel yang diamati dan eksperimen akan dihentikan setelah terjadi kegagalan kegagalan ke- $r$. Dalam penelcitian ini, terdapat $n$ pipa dari jaringan distribusi air untuk DMA Buring 3F. Misalkan T adalah variabel random dari $n$ pipa yang diamati, $f\left(t_{1}\right), f\left(t_{2}\right), \cdots, f\left(t_{r}\right)$ merupakan fungsi densitas peluang komponen yang gagal dari waktu ke-1 sampai ke- $r$ sedangkan komponen yang masih bertahan melebihi waktu dari komponen ke- $r$ dituliskan dengan $T_{r+1}, T_{r+2}, \cdots, T_{n}$ sebanyak $n-r$, sehingga diperoleh fungsi densitas peluang bersama dari $T_{r+1}, T_{r+2}, \cdots, T_{n}$ dari data yang diamati sebagai berikut:

$$
f\left(t_{1}, t_{2}, \cdots, t_{r}\right)=\frac{n !}{(n-r) !}\left[\prod_{i=1}^{n} f\left(t_{i}\right)\right]\left[\left(R\left(t_{r}\right)\right)^{n-r}\right]
$$

Dari persaman (1) diperoleh fungsi likelihood sebagai berikut:

$$
L\left(\mu_{\ln t}, \sigma_{\ln t}\right)=\frac{n !}{(n-r) !}\left[\left(\frac{1}{\prod_{i=1}^{r} t_{i}}\right)\left(\frac{1}{\sigma_{\ln t} \sqrt{2 \pi}}\right)^{r} e^{-\frac{1}{2} \sum_{i=1}^{r}\left(\frac{\ln t_{i}-\mu_{\ln t}}{\sigma_{\ln t}}\right)^{2}}\right] \cdot\left[\left(1-\Phi\left(\frac{\ln t_{r}-\mu_{\ln t}}{\sigma_{\ln t}}\right)\right)^{n-r}\right]
$$

Metode maximum likelihood digunakan untuk mengestimasi paramete-parameter berbagai distribusi dalam statistik sehingga dalam penulisan ini berdasarkan distribusi lognormal. Dari persamaan (2) diperoleh fungsi ln-likelihood dari distribusi lognormal sebagai berikut:

$$
\begin{aligned}
\ln L\left(\mu_{\ln t}, \sigma_{\ln t}\right)=\ln \left(\frac{n !}{(n-r) !}\right) & +\ln \left(\frac{1}{\prod_{i=1}^{r} t_{i}}\right)+\ln \left(\left(\frac{1}{\sigma_{\ln t} \sqrt{2 \pi}}\right)^{r}\right) \\
& +\ln \left(e^{-\frac{1}{2} \sum_{i=1}^{r}\left(\frac{\ln t_{i}-\mu_{\ln t}}{\sigma_{\ln t}}\right)^{2}}\right)+\ln \left(\left(1-\Phi\left(\frac{\ln t_{r}-\mu_{\ln t}}{\sigma_{\ln t}}\right)\right)^{n-r}\right)
\end{aligned}
$$

Dari persamaan (3) maka akan dicari turunan pertama terhadap $\mu_{\ln t}$ dan $\sigma_{\ln t}$ sebagai berikut:

$$
\frac{\partial \ln L\left(\mu_{\ln t}, \sigma_{\ln t}\right)}{\partial \mu_{\ln t}}=\frac{1}{\sigma_{\ln t}} \sum_{i=1}^{r}\left(\frac{\ln t_{i}-\mu_{\ln t}}{\sigma_{\ln t}}\right)+\frac{\left(\frac{n-r}{\sigma_{\ln t}}\right) \varphi\left(\frac{\ln t_{r}-\mu_{\ln t}}{\sigma_{\ln t}}\right)}{1-\Phi\left(\frac{\ln t_{r}-\mu_{\ln t}}{\sigma_{\ln t}}\right)}
$$

dan

$$
\frac{\partial \ln L\left(\mu_{\ln t}, \sigma_{\ln t}\right)}{\partial \sigma_{\ln t}}=-\frac{r}{\sigma_{\ln t}}+\left(\frac{1}{\sigma_{\ln t}} \sum_{i=1}^{r}\left(\frac{\ln t_{i}-\mu_{\ln t}}{\sigma_{\ln t}}\right)^{2}\right)+\left(\frac{n-r}{\sigma_{\ln t}}\right)\left(\frac{\left(\frac{\ln t_{r}-\mu_{\ln t}}{\sigma_{\ln t}}\right) \varphi\left(\frac{\ln t_{r}-\mu_{\ln t}}{\sigma_{\ln t}}\right)}{1-\Phi\left(\frac{\ln t_{r}-\mu_{\ln } t}{\sigma_{\ln t}}\right)}\right)
$$

Dari persamaan (4) dan (5) maka maximum likelihood estimator (MLE) $\hat{\mu}_{\ln t}$ dan $\hat{\sigma}_{\ln t}$ diperoleh sebagai berikut:

dan

$$
\frac{1}{\widehat{\sigma}_{\ln t}}\left(\sum_{i=1}^{r} \frac{\ln t_{i}-\widehat{\mu}_{\ln t}}{\widehat{\sigma}_{\ln t}}\right)+\left(\frac{n-r}{\widehat{\sigma}_{\ln t}}\right)\left(\frac{\varphi\left(\frac{\ln t_{r}-\widehat{\mu}_{\ln t}}{\widehat{\sigma}_{\ln t}}\right)}{1-\Phi\left(\frac{\ln t_{r}-\widehat{\mu}_{\ln t}}{\widehat{\sigma}_{\ln t}}\right)}\right)=0
$$

$$
-\frac{r}{\widehat{\sigma}_{\ln t}}+\frac{1}{\widehat{\sigma}_{\ln t}}\left(\sum_{i=1}^{r}\left(\frac{\ln t_{i}-\widehat{\mu}_{\ln t}}{\widehat{\sigma}_{\ln t}}\right)^{2}\right)+\left(\frac{n-r}{\widehat{\sigma}_{\ln t}}\right) \frac{\left(\ln t_{r}-\widehat{\mu}_{\ln t}\right)}{\widehat{\sigma}_{\ln t}}\left(\frac{\varphi\left(\frac{\ln t_{r}-\widehat{\mu}_{\ln t}}{\widehat{\sigma}_{\ln t}}\right)}{1-\Phi\left(\frac{\ln t_{r}-\widehat{\mu}_{\ln t}}{\widehat{\sigma}_{\ln t}}\right)}\right)=0
$$




\section{Nama Penulis}

Dari persamaan (6) dan (7) memiliki fungsi yang kompleks dan tidak linier karena terdapat bentuk $\frac{\varphi\left(z_{r}\right)}{1-\Phi\left(z_{r}\right)}$ dimana $z_{r}=\frac{\ln t_{r}-\widehat{\mu}_{\ln t}}{\widehat{\sigma}_{\ln t}}$. Hal ini merupakan masalah nonlinieritas sehingga diperlukan deret Taylor untuk fungsi $h\left(z_{r}\right)=\frac{\varphi\left(z_{r}\right)}{\Phi\left(-z_{r}\right)}$ pada titik sekitar $v=\Phi^{-1}\left(\frac{r}{n+1}\right)$ dengan mengabaikan orde turunan yang lebih tinggi sehingga diperoleh:

$$
\begin{aligned}
h\left(z_{r}\right) & =h(v)+\left(z_{r}-v\right) h^{\prime}(v) \\
& =h(v)-v h^{\prime}(v)+z_{r} h^{\prime}(v) \\
& =a+z_{r} b
\end{aligned}
$$

dimana $a=h(v)-v h^{\prime}(v)$ dan $b=h^{\prime}(v) \geq 0$. berikut:

Dari persamaan (7) dan (8) akan dicari estimator untuk $\hat{\mu}_{\ln t}$ sehingga dapat dinyatakan sebagai

$$
\frac{1}{\widehat{\sigma}_{\ln t}}\left(\sum_{i=1}^{r} \frac{\ln t_{i}-\widehat{\mu}_{\ln t} t}{\widehat{\sigma}_{\ln t}}\right)+\left(\frac{n-r}{\widehat{\sigma}_{\ln t}}\right)\left(a+\left(\frac{\ln t_{r}-\widehat{\mu}_{\ln t}}{\widehat{\sigma}_{\ln t}}\right) b\right)=0
$$

Sehingga diperoleh estimator $\hat{\mu}_{\ln t}$ sebgai berikut:

$$
\begin{aligned}
\hat{\mu}_{\ln t} & =\frac{\left(\sum_{i=1}^{r} \ln t_{i}\right)+(n-r)\left(b \ln t_{r}\right)+(n-r)\left(a \widehat{\sigma}_{\ln t}\right)}{(r+(n-r) b)} \\
& =p+q \hat{\sigma}_{\ln t}
\end{aligned}
$$

dimana $p=\frac{\left(\sum_{i=1}^{r} \ln t_{i}\right)-(n-r)\left(b \ln t_{r}\right)}{(r+(n-r) b)}$ dan $q=\frac{(n-r) a}{(r+(n-r) b)}$ berikut:

Dari persamaan (7) dan (8) akan dicari estimator untuk $\hat{\sigma}_{\ln t}$ sehingga dapat dinyatakan sebagai

$$
-\frac{r}{\widehat{\sigma}_{\ln t}}+\frac{1}{\widehat{\sigma}_{\ln t}}\left(\sum_{i=1}^{r}\left(\frac{\ln t_{i}-\widehat{\mu}_{\ln t}}{\widehat{\sigma}_{\ln t}}\right)^{2}\right)+\left(\frac{n-r}{\widehat{\sigma}_{\ln t}}\right)\left(\frac{\ln t_{r}-\widehat{\mu}_{\ln t}}{\widehat{\sigma}_{\ln t}}\right)\left(a+\left(\frac{\ln t_{r}-\widehat{\mu}_{\ln t}}{\widehat{\sigma}_{\ln t}}\right) b\right)=0
$$

sehingga diperoleh:

$$
\begin{array}{r}
-r \hat{\sigma}^{2} \ln t+(n-r)\left(\ln t_{r}-p\right) a \hat{\sigma}_{\ln t}+(n-r)\left(\ln t_{r}-p\right)^{2} b+\left(\sum_{i=1}^{r}\left(\ln t_{i}-p\right)^{2}\right)=0 \\
-r\left(\hat{\sigma}_{\ln t}\right)^{2}+c_{1} \hat{\sigma}_{\ln t}+c_{2}=0
\end{array}
$$

dimana

$$
c_{1}=(n-r)\left(\ln t_{r}-p\right) a \text { dan } c_{2}=(n-r)\left(\ln t_{r}-p\right)^{2} b+\left(\sum_{i=1}^{r}\left(\ln t_{i}-p\right)^{2}\right) \geq 0
$$




\section{Nama Penulis}

\begin{tabular}{|c|c|c|c|c|c|c|c|c|}
\hline$t_{i}$ & $\ln t_{i}$ & $p$ & $\left(\ln t_{i}-p\right)$ & $\left(\ln t_{i}-p\right)^{2}$ & $\mu_{\ln t}$ & $\sigma_{\operatorname{lnt}}$ & $\left(t_{i}-\mu_{\ln t}\right) / \sigma_{\ln t}$ & $\left(\left(t_{i}-\mu_{\ln t}\right) / \sigma_{\ln t}\right)^{2}$ \\
\hline 24,3 & 3,1910 & 3,5314 & $-0,3404$ & 0,1158 & 3,6853 & 0,2979 & $-1,6590$ & 2,7522 \\
\hline 24,6 & 3,2030 & 3,5314 & $-0,3284$ & 0,1079 & 3,6853 & 0,2979 & $-1,6189$ & 2,6210 \\
\hline 24,7 & 3,2076 & 3,5314 & $-0,3238$ & 0,1049 & 3,6853 & 0,2979 & $-1,6034$ & 2,5710 \\
\hline 25,3 & 3,2293 & 3,5314 & $-0,3021$ & 0,0913 & 3,6853 & 0,2979 & $-1,5307$ & 2,3430 \\
\hline 25,5 & 3,2388 & 3,5314 & $-0,2926$ & 0,0856 & 3,6853 & 0,2979 & $-1,4987$ & 2,2462 \\
\hline 26,5 & 3,2757 & 3,5314 & $-0,2557$ & 0,0654 & 3,6853 & 0,2979 & $-1,3749$ & 1,8904 \\
\hline 27,3 & 3,3078 & 3,5314 & $-0,2236$ & 0,0500 & 3,6853 & 0,2979 & $-1,2671$ & 1,6055 \\
\hline 27,9 & 3,3277 & 3,5314 & $-0,2037$ & 0,0415 & 3,6853 & 0,2979 & $-1,2002$ & 1,4405 \\
\hline 28,7 & 3,3553 & 3,5314 & $-0,1762$ & 0,0310 & 3,6853 & 0,2979 & $-1,1078$ & 1,2273 \\
\hline 29,7 & 3,3916 & 3,5314 & $-0,1398$ & 0,0195 & 3,6853 & 0,2979 & $-0,9858$ & 0,9717 \\
\hline 30,5 & 3,4166 & 3,5314 & $-0,1148$ & 0,0132 & 3,6853 & 0,2979 & $-0,9018$ & 0,8132 \\
\hline 31,1 & 3,4367 & 3,5314 & $-0,0947$ & 0,0090 & 3,6853 & 0,2979 & $-0,8345$ & 0,6965 \\
\hline 31,5 & 3,4508 & 3,5314 & $-0,0806$ & 0,0065 & 3,6853 & 0,2979 & $-0,7872$ & 0,6197 \\
\hline 32,9 & 3,4948 & 3,5314 & $-0,0366$ & 0,0013 & 3,6853 & 0,2979 & $-0,6394$ & 0,4088 \\
\hline 33,1 & 3,4991 & 3,5314 & $-0,0323$ & 0,0010 & 3,6853 & 0,2979 & $-0,6250$ & 0,3906 \\
\hline 33,3 & 3,5048 & 3,5314 & $-0,0266$ & 0,0007 & 3,6853 & 0,2979 & $-0,6058$ & 0,3670 \\
\hline 34,3 & 3,5344 & 3,5314 & 0,0030 & 0,0000 & 3,6853 & 0,2979 & $-0,5065$ & 0,2565 \\
\hline 34,3 & 3,5357 & 3,5314 & 0,0043 & 0,0000 & 3,6853 & 0,2979 & $-0,5021$ & 0,2521 \\
\hline 35,4 & 3,5667 & 3,5314 & 0,0353 & 0,0012 & 3,6853 & 0,2979 & $-0,3981$ & 0,1585 \\
\hline 35,4 & 3,5676 & 3,5314 & 0,0362 & 0,0013 & 3,6853 & 0,2979 & $-0,3952$ & 0,1562 \\
\hline 35,9 & 3,5797 & 3,5314 & 0,0483 & 0,0023 & 3,6853 & 0,2979 & $-0,3546$ & 0,1258 \\
\hline 37,3 & 3,6181 & 3,5314 & 0,0867 & 0,0075 & 3,6853 & 0,2979 & $-0,2256$ & 0,0509 \\
\hline 38,5 & 3,6496 & 3,5314 & 0,1182 & 0,0140 & 3,6853 & 0,2979 & $-0,1199$ & 0,0144 \\
\hline 39,9 & 3,6856 & 3,5314 & 0,1542 & 0,0238 & 3,6853 & 0,2979 & 0,00102 & 0,0000 \\
\hline Total & 82,2679 & & & 0,7948 & & & $-20,7412$ & 23,9789 \\
\hline
\end{tabular}

Tabel 1. Perhitungan Data Tersensor Tipe II 


\section{Jurnal Pendidikan Matematika Vol 1 No 1 Tahun 2019 Nama Penulis}

Gambar 1 menujukan ilustrasi data tersensor tipe ii untuk jaringan pipa dari awal instalasi sampai waktu analisis. Pada daerah sebelah kiri sebelum waktu analisis merupakan data jumlah pipa yang tidak tersensor atau gagal sedangkan daerah sebelah kanan merupakan data jumlah pipa yang tersensor. Diasumsikan 50 pipa tersebut identik dengan waktu instalasi sama, sehingga terdapat 24 pipa yang tidak tersensor dengan kata lain pipa tersebut mengalami kegagalan dengan jumlah kegagalan (kerusakan pipa) hanya 1 kali dan jumlah pipa yang tersensor sebanyak $n-r$ yaitu $50-24=26$ pipa dan data tersensor yang ke- $t_{r}$ adalah 39,9 sehingga $\ln t_{r}=3,6856$ yang ditunjukan pada Tabel 1 , sehingga dapat dihitung:

diperoleh:

$$
h(v)=\frac{\varphi(v)}{\Phi(-v)}
$$

$$
\begin{gathered}
v=\Phi^{-1}\left(\frac{r}{n+1}\right) \\
=\Phi^{-1}\left(\frac{24}{50+1}\right) \\
v=\Phi^{-1}(0,4706)
\end{gathered}
$$

Dari persamaan (8), (10) dan (12) diperoleh nilai $\hat{\mu}_{\ln t}=3,6853$ dan $\hat{\sigma}_{\ln t}=0,2979$.

Setelah memperoleh nilai parameter dari $\hat{\mu}_{\ln t}$ dan $\hat{\sigma}_{\ln t}$, dilanjutkan dengan menghtung interval random untuk mengestimasi parameter dari sebuah populasi apakah parameter tersebut berada dalam interval kepercayaan tersebut. Langkah pertama dengan menentukan matriks informasi $I\left(\hat{\mu}_{\ln t}, \hat{\sigma}_{\ln t}\right)$ dimana

$$
\begin{aligned}
I & =\left[\begin{array}{cc}
-\frac{\partial^{2} \ln L\left(\mu_{\ln t}, \sigma_{\ln t}\right)}{\partial \mu_{\ln t^{2}}} & -\frac{\partial^{2} \ln L\left(\mu_{\ln t}, \sigma_{\ln t}\right)}{\partial \mu_{\ln t} \partial \sigma_{\ln t}} \\
-\frac{\partial^{2} \ln L\left(\mu_{\ln t}, \sigma_{\ln t}\right)}{\partial \sigma_{\ln t} \partial \mu_{\ln t}} & -\frac{\partial^{2} \ln L\left(\mu_{\ln t}, \sigma_{\ln t}\right)}{\partial \sigma_{\ln t^{2}}}
\end{array}\right] \\
& =\left[\begin{array}{cc}
451,9856 & -233,4848 \\
-233,4848 & 540,529
\end{array}\right]
\end{aligned}
$$

Matriks kovarian $\widehat{V}$ adalah hasil invers dari matriks informasi yaitu:

$$
\begin{aligned}
& \widehat{V}=I\left(\hat{\mu}_{\ln t}, \hat{\sigma}_{\ln t}\right)^{-1} \\
& \widehat{V}=\left[\begin{array}{ll}
\widehat{V}_{11} & \widehat{V}_{12} \\
\widehat{V}_{21} & \widehat{V}_{22}
\end{array}\right] \\
& \widehat{V}=\left[\begin{array}{ll}
0,00285 & 0,00123 \\
0,00123 & 0,00238
\end{array}\right]
\end{aligned}
$$

Dengan standard error $\hat{\mu}_{\ln t}$ adalah $\operatorname{se}\left(\hat{\mu}_{\ln t}\right)=\hat{V}_{11}{ }^{1 / 2}=0,05337$ dan standard error untuk $\hat{\sigma}_{\ln t}$ adalah $\operatorname{se}\left(\hat{\sigma}_{\ln t}\right)=\hat{V}_{22}{ }^{1 / 2}=0,0488$.

Langkah kedua adalah menentukan interval konfidensi untuk $\mu_{\ln t}$ dan $\sigma_{\ln t}$ dengan pendekatan nilai pivot $Z_{1}=\frac{\widehat{\mu}_{\ln t}-\mu_{\ln t}}{s e\left(\widehat{\mu}_{\ln t}\right)}$ dan $Z_{2}=\frac{\widehat{\sigma}_{\ln t}-\sigma_{\ln t}}{s e\left(\widehat{\sigma}_{\ln t}\right)}$ yang berdistribusi Normal $(0,1)$ dengan taraf signifikan 0,05 $(\alpha)$ sehingga interval konfidensi untuk $\mu_{\ln t}$ yaitu $\hat{\mu}_{\ln t} \pm z_{0,05} \operatorname{se}\left(\hat{\mu}_{\ln t}\right)$ dan interval konfidensi untuk $\sigma_{\ln t}$ yaitu $\hat{\sigma}_{\ln t} \pm z_{0,05} \operatorname{se}\left(\hat{\sigma}_{\ln t}\right)$. Dari Tabel $z$ (distribusi normal standar) diperoleh nilai dari $z_{0,05}=1,96$ untuk interval konfidensi $\mu_{\ln t}$ dan $\sigma_{\ln t}$ sebagai berikut: 


\section{Nama Penulis}

$$
\begin{gathered}
P\left(\hat{\mu}_{\ln t}-z_{\alpha / 2} \operatorname{se}\left(\hat{\mu}_{\ln t}\right)<\mu_{\ln t}<\hat{\mu}_{\ln t}+z_{\alpha / 2} \operatorname{se}\left(\hat{\mu}_{\ln t}\right)\right)=1-\alpha / 2 \\
P\left(3,6853-(1,96)(0,05337)<\mu_{\ln t}<3,6853+(1,96)(0,05337)\right)=1-0,025 \\
P\left(3,58071<\mu_{\ln t}<3,7899\right)=0,975
\end{gathered}
$$

Jadi, batas konfidensi bawah untuk $\mu_{\ln t}$ adalah 3,58071 dan batas konfidensi atas adalah 3,7899.

$$
\begin{gathered}
P\left(\hat{\sigma}_{\ln t}-z_{\alpha / 2} \operatorname{se}\left(\hat{\sigma}_{\ln t}\right)<\sigma_{\ln t}<\hat{\sigma}_{\ln t}+z_{\alpha / 2} \operatorname{se}\left(\hat{\sigma}_{\ln t}\right)\right)=1-\alpha / 2 \\
\left(0,2979-(1,96)(0,0488)<\sigma_{\ln t}<0,2979+(1,96)(0,0488)\right)=1-0,025 \\
P\left(0,20228<\sigma_{\ln t}<0,39358\right)=0,975
\end{gathered}
$$

Jadi, batas konfidensi bawah untuk $\sigma_{\ln t}$ adalah 0,20228 dan batas konfidensi atas adalah 0,39358.

Fungsi densitas peluang dari distribusi lognormal untuk data jaringan pipa air dan grafik fungsi densitas peluang:

$$
f(t)=\frac{1}{0,2979 t} \varphi\left(\frac{\ln t-3,6853}{0,2979}\right), t>0
$$

dimana

$$
\varphi\left(\frac{\ln t-3,6853}{0,2979}\right)=\frac{1}{\sqrt{2 \pi}} e^{-\frac{1}{2}\left(\frac{\ln t-3,6853}{0,2979}\right)^{2}}
$$

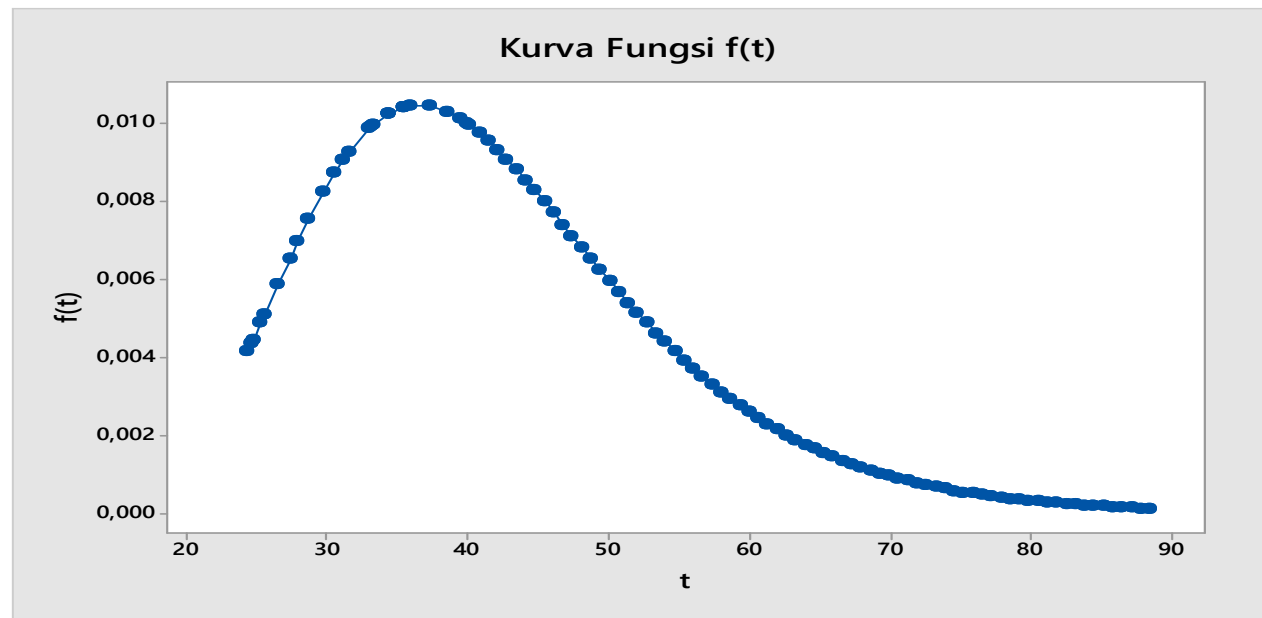

Gambar 2. Kurva Fungsi Densitas Peluang dari Data Jaringan Pipa Air

Fungsi reliabilitas dari distribusi lognormal untuk data jaringan pipa air dan kurva fungsi reliabilitas:

$\operatorname{dimana} \Phi(\infty)=1$

$$
R(t)=1-\Phi\left(\frac{\ln t-3,6853}{0,2979}\right)
$$




\section{Nama Penulis}



Gambar 3. Kurva Fungsi Reliabilitas dari Data Jaringan Pipa Air

Dari persamaan (13) dan (14) diperoleh fungsi hazard dari distribusi lognormal untuk laju kerusakan pipa air sebagai berikut:

$$
\begin{aligned}
& h(t)=\frac{f(t)}{R(t)} \\
& h(t)=\frac{\frac{1}{0,2979 t} \varphi\left(\frac{\ln t-3,6853}{0,2979}\right)}{1-\Phi\left(\frac{\ln t-3,6853}{0,2979}\right)}
\end{aligned}
$$

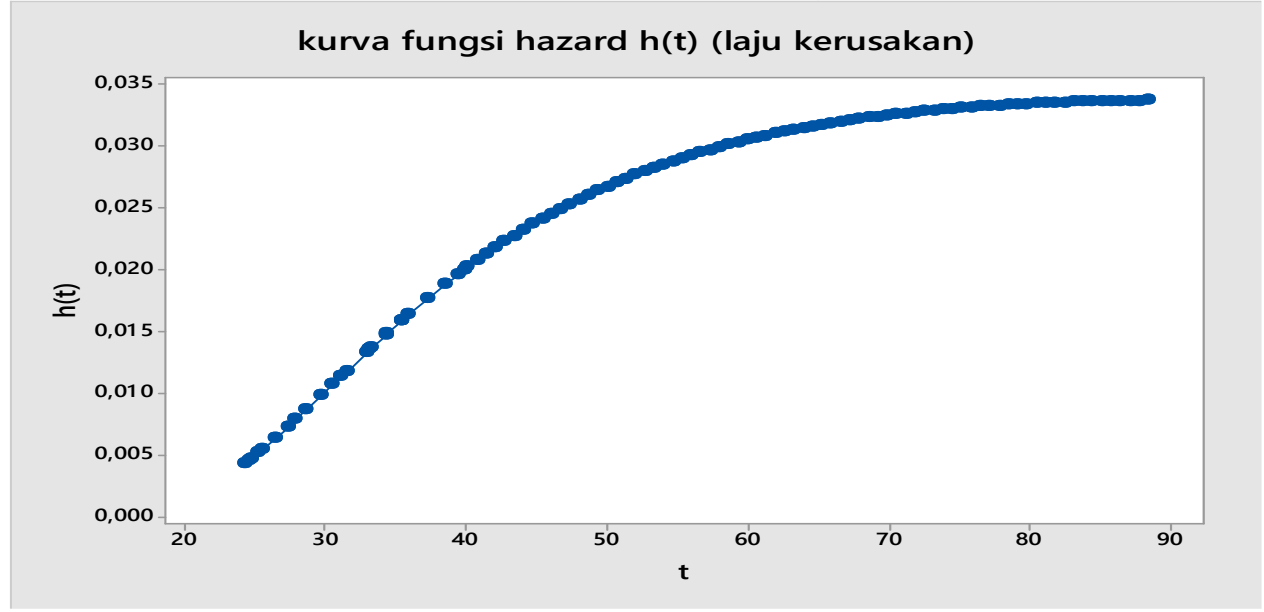

Gambar 4. Kurva Laju Kerusakan Pipa air

Dari persamaan (14), maka dapat dihitung peluang daya tahan pipa berumur 45 dan 55 tahun masingmasing yaitu 0,34 dan 0,14 sehingga dari persamaan (15) diperoleh laju kerusakan pipa berumur 45 dan 55 tahun masing-masing yaitu 0,024 dan 0,029 .

\section{Simpulan dan Saran}

Laju kerusakan pipa air pada fungsi hazard berbanding terbalik dengan reliabilitas pipa dari tahun ke tahun dimana semakin lama masa pakai suatu pipa maka semakin kecil pula peluang daya tahan pipa dengan meningkatnya laju kerusakan pipa. Dengan demikian, penulis menyarankan PDAM harus meningkatkan kinerja perawatan dan pemeliharaan jaringan pipa air sehingga kuantitas air yang didistribusikan merata ke seluruh konsumen dan juga berdampak positif bagi kualitas pipa karena dengan berkurangnya udara di dalam pipa maka peluang terjadinya turbulensi dan fluktuasi sangat kecil. 


\section{Nama Penulis}

\section{Daftar Pustaka}

Coz, R. D. (1972). Regression Models and Life-Tables. Journal of the Royal Society, Series B (Methodological), 34(2), 187-220.

Delvion, E. B. S., S. Abusini dan H. Pramoedyo. (2018). Reliability Model of Water Distribution Network Using Minimum Cut Set Approach Based on Rayleigh Distribution. American Journal of Engineering Research (AJER), 7(4), 194 - 201.

Dube, S., B. Pradhan, dan D. Kundu. (2011). Parameter Estimation of the Hybrid Censored Log-normal Distribution. Journal of Statistical Computation and Simulation, 81(3), 275-287.

Lawless, J. F. (2003). Statistical Models and Methods for Lifetime Data, Second Edition. John wiley and sons, Inc. New Jersey-USA.

Panahi, H. dan S. Asadi. (2011). Estimation of the Weibull Distribution Based on Tipe II Censored Samples. Applied Mathematical Sciences, 5(52), 2549-2558.

Rausand, M. dan A. Hoyland. (2004). System Reliability Theory: Models, Statiscal Methods, and Application, Second Edition. John Wiley and Sons, Inc. New Jersey-USA. 